\title{
Assessment of corneal astigmatism following frown and straight incision forms in sutureless manual small incision cataract surgery
}

This article was published in the following Dove Press journal:

Clinical Optometry

22 April 2016

Number of times this article has been viewed

\section{Angela Ofeibea Amedo \\ Kwadwo Amoah \\ Nana Yaa Koomson \\ David Ben Kumah \\ Eugene Appenteng Osae}

Department of Optometry and Visual Science, Kwame Nkrumah University of Science and Technology, Kumasi, Ghana
Correspondence: Eugene Appenteng Osae

Department of Optometry and Visual Science, Kwame Nkrumah University of Science and Technology, Private Mail Bag, University Post Office, Kumasi, Ghana

$\mathrm{Tel}+233207121298$

Email osaeappen@gmail.com

\begin{abstract}
To investigate which of two tunnel incision forms (frown versus straight) in sutureless manual small incision cataract surgery creates more corneal astigmatism. Sixty eyes of 60 patients who had consented to undergo cataract surgery and to partake in this study were followed from baseline through $>12$-week postoperative period. Values of preoperative and postoperative corneal astigmatism for the 60 eyes, measured with a Bausch and Lomb keratometer, were extracted from the patients' cataract surgery records. Residual astigmatism was computed as the difference between preoperative and postoperative keratometry readings. Visual acuity was assessed during the preoperative period and at each postoperative visit with a Snellen chart at $6 \mathrm{~m}$. Fifty eyes of 50 patients were successfully followed-up on. Overall, the mean residual astigmatism was $0.75 \pm 0.12$ diopters. The differences in mean residual astigmatism between the two different incision groups were statistically significant $(t[48]=6.33, P<0.05)$; frown incision group recorded $1.00 \pm 0.12$ diopters, whereas the straight incision group recorded $0.50 \pm 0.12$ diopters. No significant difference was observed between male and female groups ( $\mathrm{t}[48]=0.24, P>0.05)$. Residual corneal astigmatism in the frown incision group was significantly higher than in the straight incision group. Fisher's exact test did not reveal a significant association between incision forms and visual acuity during the entire postoperative period $(P>0.05)$.
\end{abstract}

Keywords: cataract, residual corneal astigmatism, frown incision, straight incision

\section{Introduction}

Cataract is an eye condition in which the human crystalline lens becomes opaque and invariably affects vision. ${ }^{1-4}$ It mostly affects the aged, but young people may suffer from congenital forms of the condition. ${ }^{1,5,6}$ The causes and risk factors for cataract are many and varied. Some of them include genetics, sex, race, metabolic diseases, trauma to the eyes, radiation, use of certain drugs, and lifestyle. ${ }^{7,8}$

It is common for ophthalmic clinicians to attempt to improve the vision of persons with early cataracts - either by the use of spectacle prescription and/or antiglare devices. ${ }^{9}$ Sometimes, clinicians may also prescribe antioxidant-rich supplements and diets that are believed to retard the lens clouding process. ${ }^{10,11}$ In spite of these approaches, vision is often improved when cataract is ultimately removed by surgery and patients undergo subsequent visual rehabilitation. . $^{3,12,13}$

Surgical techniques for cataract extraction have undergone major advancement from intracapsular extraction to the present day phacoemulsification. Phacoemulsification offers desirable anatomical and functional results following cataract surgery. The technique is however not widely used in some parts of the developing world for reasons such as higher cost and expertise. The most widely used surgical technique for cataract 
extraction in third world countries is the sutureless manual small incision cataract surgery (MSICS). MSICS is reportedly able to offer good anatomical and functional results following cataract surgery. Presently, it remains the most cost-effective method for cataract extraction in developing countries.

However, visual outcome after MSICS and other forms of cataract surgery may rarely not be desirable. The reasons for a poor visual outcome after cataract surgery are indefinite. Some studies have implicated surgeon's experience, existing ocular and systemic comorbidities of the patient, aging, and some refractive complications. ${ }^{14-16}$

Significant and oftentimes unwanted residual corneal astigmatism (RCA) could affect visual outcome following cataract surgery. It has been identified as an inevitable contributory factor to the sometimes poor visual outcome after cataract surgery. ${ }^{17}$ Some studies have stated that RCA can be significantly blinding as the in situ cataractous lens and can severely affect visual function. ${ }^{18,19}$ RCA has been an influence in the evolution of cataract surgical techniques and incision types - in attempts to improve visual outcome by minimizing or preventing RCA. ${ }^{20,21}$ The type, size, and location of incisions, general surgical "insults" to corneal architecture, a surgeon's experience, and other factors are said to also influence RCA. ${ }^{17,22}$

Herein, we attempted to compare the amounts of RCA between two groups of patients who underwent frown and straight incision forms of MSICS at a local hospital. We also studied visual acuity (VA) differences and changes between these two groups during the entire study period.

\section{Methods}

\section{Participants}

The participants were 60 persons with cataracts who had consented to undergo cataract surgery at a local hospital. All the individuals included in this study had operable cataracts with no obvious corneal abnormality and had also consented to participate in this study. They comprised 27 males and 33 females. Cataract patients at this local hospital are routinely assigned to either the frown or straight MSICS incision form by the surgeon in a simple random fashion. After explaining the research to the participants, informed consent was sought from them to have information relevant to this study extracted from their cataract surgery records at each visit, for data analysis. This mainly comprised VA and keratometry (k-) readings. Patients could withdraw from the study at their own will. Ethical approval was not sought as per the Kwame Nkrumah University of Science and Technology Institutional policy. All procedures conformed to the tenets of the Declaration of Helsinki.

\section{Procedures}

K-readings were obtained for each individual using a Bausch and Lomb one position variable doubling keratometer (model number K-6003). The k-readings at each visit were repeated thrice and the average recorded. Uncorrected vision (distance) for each participant was determined using a Snellen chart with backlight luminance of $160 \mathrm{~cd} / \mathrm{m}^{2}$, at $6 \mathrm{~m}$. All of these procedures were done during the preoperative period (before surgery) and then at each postoperative visit at intervals of the first to third week, the fourth to eleventh week, the 12th week and beyond - all following the day of cataract surgery.

Preoperative corneal astigmatism (PCA) was determined as the initial difference between k-reading values for the two principal corneal meridians of each participant's eye before surgery. RCA was obtained in the same way; as the difference between the PCA and the corneal astigmatism at specific postoperative visits. Values of both the PCA and RCA were kept in units of diopters (D). All k-readings obtained were approximated to the nearest measurable $\mathrm{D}$ value.

Data were analyzed using SPSS version 20 (IBM Corporation, Armonk, NY, USA). Differences in mean PCA and RCA between groups were studied using bivariate independent Student's $t$-test statistics. Fisher's exact test was used to test for associations between comparable categorical groups. Microsoft Excel (2007) was used to plot graphs. A $P$-value $<0.05$ was considered significant.

\section{Results}

\section{Participants' demographics}

Fifty eyes of 50 out of the 60 patients were successfully followed-up on for the period under study. The other ten were lost to follow-up. The mean age of these study participants was $64.34 \pm 15.64$ years. Table 1 is a cross tabulation of the sex and the incision groups of the 50 study participants.

\section{Pattern of corneal astigmatism}

The study showed that there was no statically significant difference in PCA between the incision groups $(P=0.321)$ as well as between the sex groups $(P>0.05)$. All participants had an

Table I Cross tabulation of participants' sex per incision group

\begin{tabular}{lllll}
\hline & & \multicolumn{3}{l}{ Type of incision } \\
\cline { 3 - 5 } & & $\begin{array}{l}\text { Frown } \\
\text { (n) }\end{array}$ & $\begin{array}{l}\text { Straight } \\
\text { (n) }\end{array}$ & $\begin{array}{l}\text { Total } \\
\text { (n) }\end{array}$ \\
\hline Sex of participant & Male & 11 & 12 & 23 \\
& Female & 12 & 15 & 27 \\
Total & & 23 & 27 & 50 \\
\hline
\end{tabular}


overall mean PCA of $1.00 \pm 0.12 \mathrm{D}$; mean PCA value for the frown incision group was $1.00 \pm 0.12 \mathrm{D}$ whereas mean PCA for the straight incision group was $1.25 \pm 0.12 \mathrm{D}$

However, PCA levels dropped to values of $\sim 0.25 \mathrm{D}$ within the first 3 weeks following surgery. Levels of corneal astigmatism began to rise from the fourth week through the eleventh week and then remained steady at the 12th week and beyond (Figure 1).

The differences in mean RCA for the incision groups, as studied using independent Student's $t$-test, were observed to be statistically significant during the entire postoperative period $(P<0.05)$. At all the set intervals of the postoperative visits, the recorded mean RCA values for the frown incision were higher than that recorded for the straight incision $(P<0.05)$. The frown incision group showed RCA values that were approximately twice as high as that recorded for the straight incision group; RCA at the 12th week and beyond was $1.00 \pm 0.12 \mathrm{D}$ for the frown incision group, whereas that for the straight incision group was $0.50 \pm 0.12 \mathrm{D}$ (Figure 1).

In studying the trend in corneal astigmatism between male and female groups, we detected that there was no significant difference in their mean RCA $(P>0.05)$. This observation remained the same during the entire postoperative period. The mean RCA recorded at the end of the study for both male and female groups was $\sim 0.75 \pm 0.12 \mathrm{D}$ (Figure 2).

It was interesting to observe that intra-group variations in mean RCA, that is for male versus female groups and frown versus straight incision groups, were not uniform within the first and third week of the postoperative period. The variations at this period as observed for the intra-incisions group (Figure 1) was statistically significant $(t[39.85]=2.10$, $P=0.042)$ but was the opposite for the intra-sex group (Figure 2) $(t[41.84]=0.82, P=0.42)$.

\section{VA changes}

There was a general improvement in VA after extraction of the cataract. At baseline, $48 \%$ of the participants presented with a VA of hand-movement and $30 \%$ of them presented with an unaided VA of counting fingers. At the end of the study, $24 \%$ of them had an uncorrected VA of $6 / 18$, whereas $18 \%$ had unaided VA of $6 / 12$ with a few reading $6 / 9$ on the Snellen chart.

Figure 3 is a summary of the pattern and distribution of VA among the study participants. Fisher's exact test showed that there was no statistically significant association between VA and type of incision; for the frown and straight incision forms, $P>0.05$ at all stages of the study.

\section{Discussion}

Several studies have shown alterations in the power of preoperative astigmatism following cataract surgery. ${ }^{16,20,21,23-25}$ Our study participants had a recorded mean age of $64.34 \pm 15.64$ years. This agrees with what is reported in many literature sources that cataract remains a common condition among people in their fifth decades of life and beyond. The aged are frequently at risk of metabolic diseases that have an influence on the development of cataract. ${ }^{1,7,10}$ There could be younger persons with cataracts as found among the few

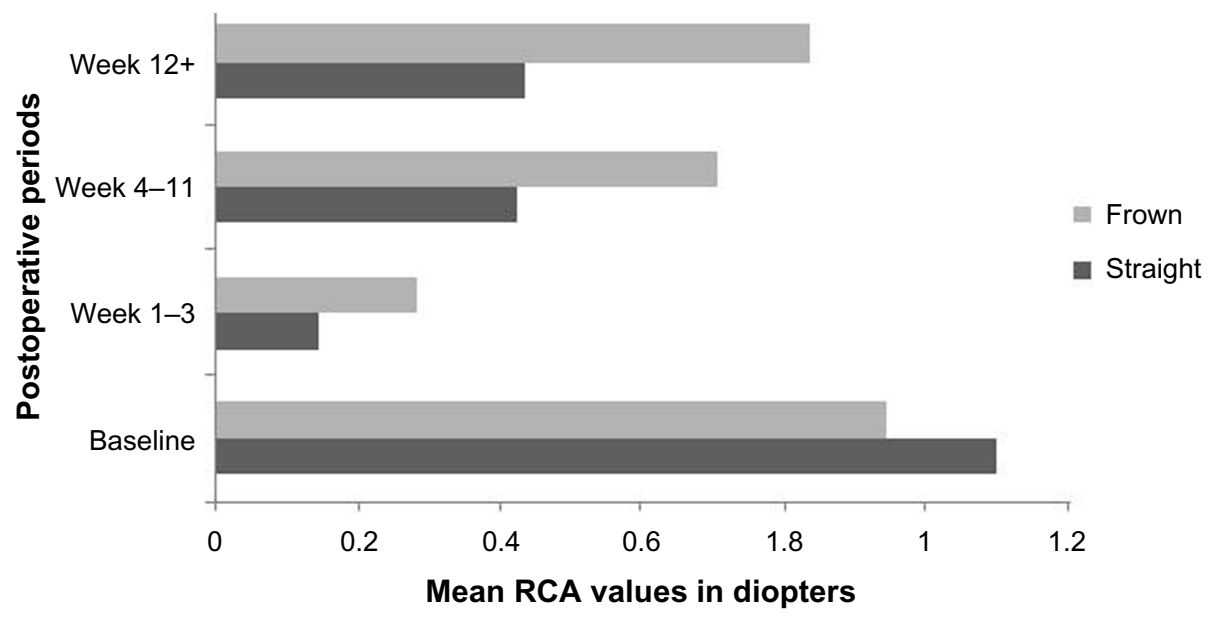

Figure I Trend in mean residual corneal astigmatism (RCA) per incision group over the study period. 


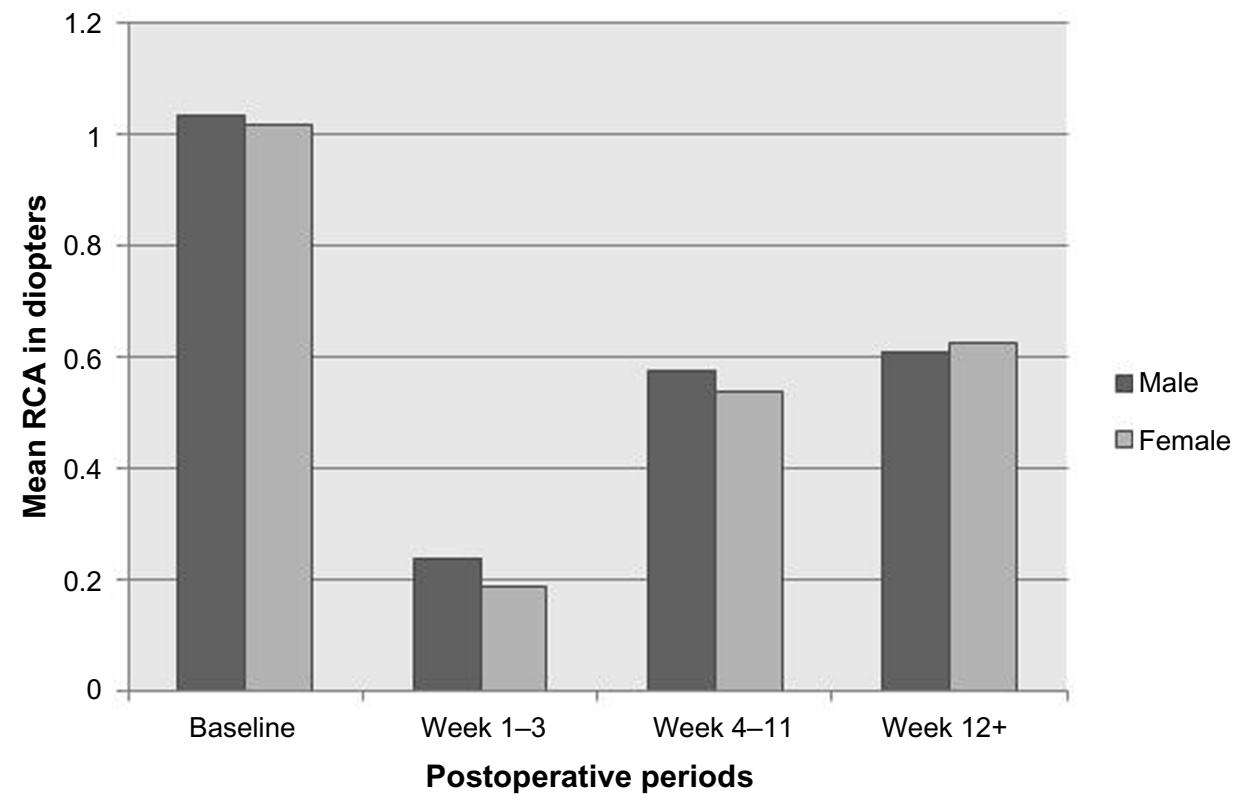

Figure 2 Variation in mean residual corneal astigmatism (RCA) according to sex of participants.

outliers in this study who may suffer cataracts congenitally or in their formative years form trauma, radiation, drugs, and other causes. ${ }^{1,5,26,27}$

All of the 50 participants were recorded to have the same amount of RCA. This was however not the situation in one study where only $75 \%$ of the study subjects were recorded to have RCA. ${ }^{28}$ Whether or not a patient will suffer significant RCA following cataract surgery has been linked to factors such as the patient's physiological characteristics, surgeon's experience, disease, and several others. ${ }^{22,29}$

The overall mean RCA $(1.00 \pm 0.12 \mathrm{D})$ recorded in our study falls between what other studies have reported. One

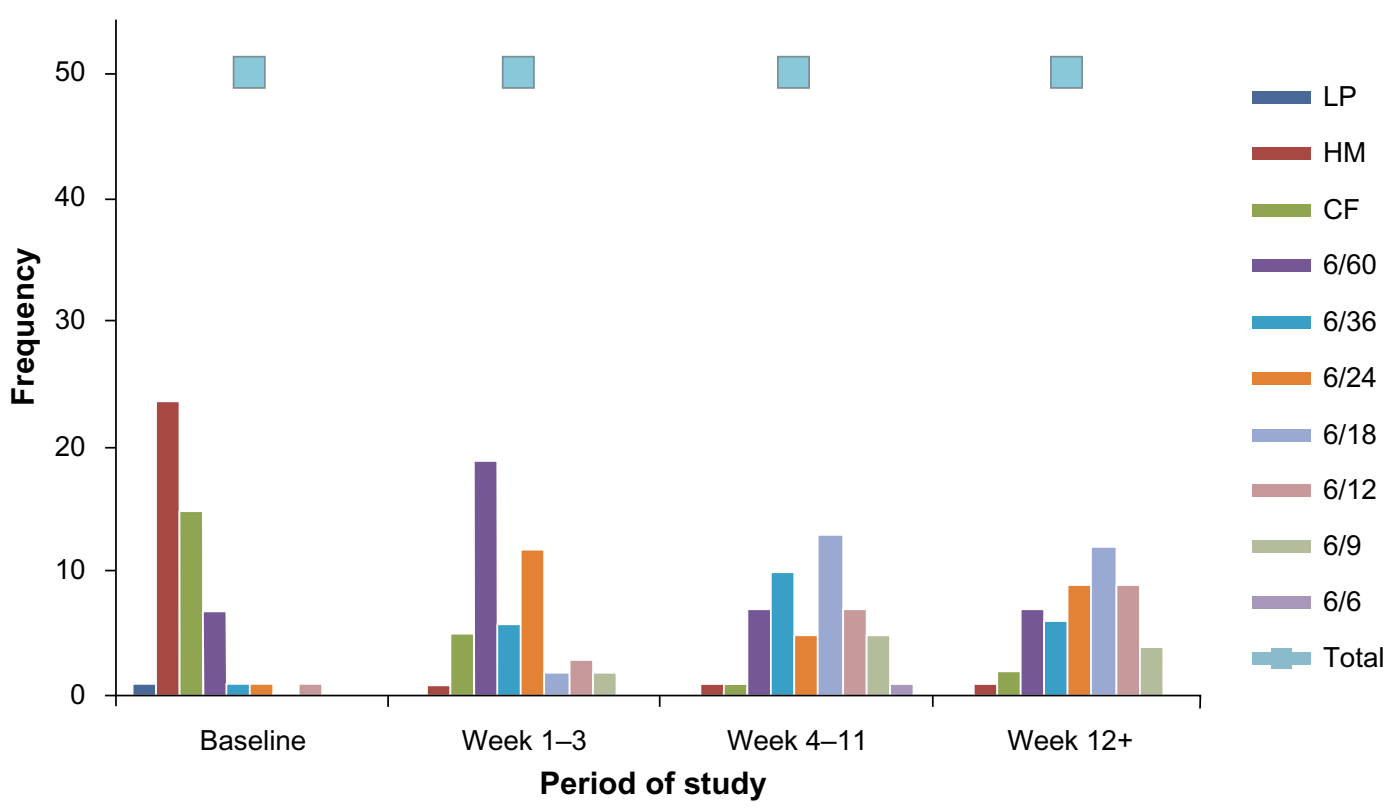

Figure 3 Visual acuity changes among study participants over the study period. Abbreviations: LP, light perception; HM, hand movement; CF, counting fingers. 
study reported a value (1.85 D) higher than what was found in our study, whereas another study recorded an RCA value $(0.525 \pm 0.804)$ lower than what is reported in our study. ${ }^{16,30}$ The overall mean RCA value of our study is however closer to what $(1.30 \mathrm{D})$ another study reported. ${ }^{23}$ The level of RCA has been found, in other studies, to be associated with preoperative corneal astigmatism present in a person's eye prior to surgery. Others have linked the levels of RCA to the sites of the tunnel incision, corneal biomechanical properties, types and size of incision. Corneal hysteresis and other physiological differences of individual patients may have their own possible influences on RCA. ${ }^{31,32}$

While certain limitations of our study did not allow for further probing into the variations of RCA observed, the observed intra-group variations in the levels of RCA could be linked to corneal rigidity and thickness. General "surgical insults" to the cornea, corneal viscoelasticity, and ocular hypotony resulting from aqueous escape during cataract surgery could also influence the variations in RCA. ${ }^{33-35}$

Even though our study reports a statistically significant difference in the mean RCA values between the frown and straight incision groups $(P<0.05)$, another study recorded a statistically insignificant difference $(P=0.062)$ between the frown and straight incision groups. That other study also reported that the frown and straight incision forms caused more RCA compared to a (V-shape) chevron incision form. ${ }^{25}$

Thus, it may be of interest for optometrists, particularly those in parts of the developing world where MSICS exists, to know what incision form a cataract patient is assigned in order to adequately assess the postoperative cataract patient for the presence of significantly reduced astigmatism. This will inform them about the best refractive correction to prescribe for such patients to ensure these patients have optimal VA following surgery.

Figure 3 shows there was a general improvement in VA during the entire postoperative period. Cataract surgery has been found, in most studies, as necessary for improvement in visual function and quality of life. This improved vision however, often gets better upon correction of the residual refractive errors - including RCA, with spectacles or contact lenses after the surgery. ${ }^{13,28,36,37,38}$

As this study could posit, a slight improvement in VA following surgery is enough for some patients to default postoperative visits because such patients "see better than they did before surgery". We lost $20 \%$ of the participants to follow-up; perhaps, the improvement in uncorrected VA, as they may have subjectively appreciated, could be a reason why some refused to show up for postoperative care and management. This is a common occurrence in most clinics across the developing world.

It is noteworthy to mention that cataract patients in some developing countries would have to wait until their vision becomes significantly impaired - often to an uncorrected VA of hand-movement before they are admitted for surgery. Most ( $>48 \%$ ) of our patients presented with a VA of handmovement or worse prior to surgery. A possible explanation may be the incommensurately low number of cataract surgeons compared to higher number of cataract patients in these parts of the world. ${ }^{39}$

\section{Conclusion}

We found that mean RCA was higher in the frown incision group than straight incision group. The difference in mean RCA for the incision groups was statistically significant $(P<0.05)$ but was not so for the sex groups $(P>0.05)$. There was a general improvement in VA, but this observation did not have any statistically significant association with the incision forms during the entire study period $(P>0.05)$, at all intervals of the postoperative period.

\section{Recommendation}

Future studies should consider including assessments of corneal biomechanical properties as these properties could provide useful insights into RCA findings.

\section{Acknowledgments}

The authors would like to extend their gratitude to the following personnel at the eye care facility for their help during data collection: Evelyn Sarpong (enrolled nurse), Afia Nkansah Asantewaa (OD), Akwasi Ahmed (MD), Sumaila Mohamadu (OD), Benjamin Brifa Bempong (OD), and Killian Asampana Asosega (statistician).

\section{Disclosure}

The authors have no conflicts of interest to disclose.

\section{References}

1. Khurana AK. Diseases of the lens Comprehensive Ophthalmology. 4 ed. India: New Age International ${ }^{\circledR}$, Limited; 2007:167-200.

2. Pascolini D, Mariotti SP. Global estimates of visual impairment: 2010. Br J Ophthalmol. 2011;96(5):614-618.

3. Gyasi M, Amoaku W, Asamany D. Barriers to cataract surgical uptake in the upper east region of Ghana. Ghana Med J. 2007;41(4):167-170.

4. Guzek JP, Anyomi FK, Fiadoyor S, Nyonator F. Prevalence of blindness in people over 40 years in the Volta region of Ghana. Ghana Med J. 2006;39(2):55-62.

5. Roberts JE. Ultraviolet radiation as a risk factor for cataract and macular degeneration. Eye Contact Lens. 2011;37(4):246-249. 
6. Courtright P, Bowman R, Gilbert C, Lewallen S, van Dijk K, Yorston D. Childhood cataract in Africa. Veenendaal, the Netherlands: Dark and Light Blind Care; 2008.

7. Chang JR, Koo E, Agrón E, et al. Risk factors associated with incident cataracts and cataract surgery in the Age-related Eye Disease Study (AREDS): AREDS report number 32. Ophthalmology. 2011;118(11):2113-2119.

8. Mohammad S, Khan SU, FCPS SUKF. Factors responsible for Traumatic Cataract and its effects on visual acuity. An Official Journal of Peshawar Medical College. 2012;10(1):82.

9. Sharma NG. Aravind Eye Care System-Compassion in Action; 2014. Available from: http://sdmimd.ac.in/SDMRCMS/cases/CIM2014/1. pdf. Accessed February 27, 2016.

10. Fletcher AE. Free radicals, antioxidants and eye diseases: evidence from epidemiological studies on cataract and age-related macular degeneration. Ophthalmic Res. 2010;44(3):191-198.

11. Mvitu M, Longo-Mbenza B, Tulomba D, Nge A. Regular, high, and moderate intake of vegetables rich in antioxidants may reduce cataract risk in Central African type 2 diabetics. Int J Gen Med. 2012;5: 489-493.

12. Aruta A, Marenco M, Marinozzi S. [History of cataract surgery]. Med Secoli. 2009;21(1):403-428.

13. Fong CS, Mitchell P, Rochtchina E, Teber ET, Hong T, Wang JJ. Correction of visual impairment by cataract surgery and improved survival in older persons: the Blue Mountains Eye Study cohort. Ophthalmology. 2013;120(9):1720-1727.

14. Chakrabarti A. Cataract Surgery in Diseased Eyes. JP Medical Ltd; 2014.

15. Wong TY. Effect of increasing age on cataract surgery outcomes in very elderly patients. BMJ. 2001;322(7294):1104-1106.

16. Behndig A, Montan P, Stenevi U, Kugelberg M, Zetterström C, Lundström M. Aiming for emmetropia after cataract surgery: Swedish National Cataract Register study. J Cataract Refract Surg. 2012;38(7):1181-1186.

17. Raiyawa S, Jenchitr W, Yenjitr B, Tapunya M. Visual acuity in patients having cataractsurgery by differenttechniques.JMedAssocThai.2008;91(Suppl 1): S92-S101.

18. Smith JS. Eye diseases in hot climates. 4 ed. India: Elsevier India Private Limited; 2003.

19. Read SA, Vincent SJ, Collins MJ. The visual and functional impacts of astigmatism and its clinical management. Ophthalmic Physiol Opt. 2014;34(3):267-294.

20. Yao K, Tang X, Ye P. Corneal astigmatism, high order aberrations, and optical quality after cataract surgery: microincision versus small incision. J Refract Surg. 2006;22(9 Suppl):S1079-S1082.

21. Elkady B, Alió JL, Ortiz D, Montalbán R. Corneal aberrations after microincision cataract surgery. J Cataract Refract Surg. 2008;34(1):40-45.

22. Odugbo OP, Babalola OE, Morgan RE. Influence of rank of surgeon on the outcome of cataract surgery in Plateau State Nigeria. Jos J Med. 2011;5(2):212-216.
23. Achar A, Kadri R, Hegde S, Kudva A, Devika P, John V. Surgically induced astigmatism following cataract surgery: A comparative study. Int J A.J. Inst Med Sci. 2013;2(1):44.

24. Cho YK, Kim MS. Perioperative modulating factors on astigmatism in sutured cataract surgery. Korean J Ophthalmol. 2009;23(4): 240-248.

25. Jauhari N, Chopra D, Chaurasia RK, Agarwal A. Comparison of surgically induced astigmatism in various incisions in manual small incision cataract surgery. Int J Ophthalmol. 2014;7(6):1001-1004.

26. Read SA, Collins MJ, Carney LG. A review of astigmatism and its possible genesis. Clin Exp Optom. 2007;90(1):5-19.

27. Dobson V, Miller JM, Harvey EM. Corneal and refractive astigmatism in a sample of 3- to 5-year-old children with a high prevalence of astigmatism. Optom Vis Sci. 1999;76(12):855-860.

28. Adio AO, Aruoto N. Induced astigmatism after cataract surgery-a retrospective analysis of cases from the University of Port Harcourt Teaching Hospital, Nigeria. Afr Vis Eye Health. 2011;70(2): $75-80$.

29. Roberts TV, Lawless M, Bali SJ, Hodge C, Sutton G. Surgical outcomes and safety of femtosecond laser cataract surgery: a prospective study of 1500 consecutive cases. Ophthalmology. 2013;120(2):227-233.

30. Aruotu N, UzoDike E. Prevalence of astigmatism in post operative cataract in University of Port Harcourt Teaching Hospital, Nigeria. $J$ Med Med Sci. 2011;2(1):632-637.

31. Matsumoto Y, Hara T, Chiba K, Chikuda M. Optimal incision sites to obtain an astigmatism-free cornea after cataract surgery with a $3.2 \mathrm{~mm}$ sutureless incision. J Cataract Refract Surg. 2001;27(10):1615-1619.

32. Denoyer A, Ricaud X, Van Went C, Labbé A, Baudouin C. Influence of corneal biomechanical properties on surgically induced astigmatism in cataract surgery. J Cataract Refract Surg. 2013;39(8):1204-1210.

33. Berdahl JP. Cataract surgery to lower intraocular pressure. Middle East Afr J Ophthalmol. 2009;16(3):119.

34. Hjortdal JØ. Regional elastic performance of the human cornea. J Biomech. 1996;29(7):931-942.

35. Elsheikh A, Wang D, Brown M, Rama P, Campanelli M, Pye D. Assessment of corneal biomechanical properties and their variation with age. Curr Eye Res. 2007;32(1):11-19.

36. Wang L, Dixit L, Weikert MP, Jenkins RB, Koch DD. Healing changes in clear corneal cataract incisions evaluated using Fourierdomain optical coherence tomography. J Cataract and Refract Surg. 2012;38(4):660-665.

37. Naeser K. Assessment of surgically induced astigmatism; call for an international standard. $J$ Cataract and Refract Surg. 1997;23(9):1278-80.

38. Sabesan R, Jeong TM, Carvalho L, Cox IG, Williams DR, Yoon G. Vision improvement by correcting higher-order aberrations with customized soft contact lenses in keratoconic eyes. Opt Lett. 2007;32(8):1000-1002.

39. Tabin G, Chen M, Espandar L. Cataract surgery for the developing world. Curr Opin Ophthalmol. 2008;19(1):55-59.
Clinical Optometry

\section{Publish your work in this journal}

Clinical Optometry is an international, peer-reviewed, open access journal publishing original research, basic science, clinical and epidemiological studies, reviews and evaluations on clinical optometry. All aspects of patient care are addressed within the journal as well as the practice of optometry including economic and business analyses. Basic and clinical Submit your manuscript here: http://www.dovepress.com/clinical-optometry-journal

\section{Dovepress}

research papers are published that cover all aspects of optics, refraction and its application to the theory and practice of optometry. The manuscript management system is completely online and includes a very quick and fair peer-review system, which is all easy to use. Visit http://www.dovepress. com/testimonials.php to read real quotes from published authors. 